\title{
Sobre a intencionalidade da política industrializante do Brasil na década de 1930
}

\author{
On the intentionality of the industrializing \\ politics of Brazil in the 1930s
}

PEDRO CEZAR DUTRA FONSECA*,**

\begin{abstract}
RESUMO: A partir das contribuições de teóricos institucionais, a proposta generalizada, iniciada com o trabalho de Celso Furtado, de que o expressivo crescimento da indústria de transformação brasileira na década de 1930 aconteceu sem intenção ou consciência da administração federal, pois derivou da política de defesa da exportação do café, é criticada. Por isso, depois de reconstruir o pensamento de Furtado sobre o assunto, argumentamos que naquela década havia evidências empíricas suficientes para mostrar a intenção e a administração em direção à industrialização, de modo que não possa ser considerado um mero "subproduto" das políticas monetária e cambial a defesa da economia cafeeira.

PALAVRAS-CHAVE: Governo Vargas; economia brasileira; Celso Furtado; grande depressão dos anos 1930; indústria brasileira.
\end{abstract}

ABSTRACT: From the contributions of institutional theorists, the widespread proposition, begun with Celso Furtado's work, that the significant growth of the Brazilian transformation industry in the 1930s happened with no intention or awareness from the federal administration since it derived from the policy of defense of the coffee export is criticized. For this matter, after rebuilding Furtado's thought on the subject, we argue that by that decade there was enough empirical evidence to show the intent and the administration towards industrialization so that it cannot be considered a mere "byproduct" of the exchange and monetary policies regarding the defense of the coffee economy.

KEYWORDS: Vargas administration; Brazilian economy; Celso Furtado; great depression of the 1930s; Brazilian industry.

JEL Classification: N16; N26; O14; O43; O54.

\footnotetext{
* Professor titular do Departamento de Ciências Econômicas da Universidade Federal do Rio Grande do Sul - UFRGS, Porto Alegre/RS, Brasil. E-mail: Pedro.fonseca@ufrgs.br. Submetido: 4/Junho/2002; Aprovado: 6/Agosto/2002.

* Agradeço a Wilson Suzigan e a Octavio Augusto Camargo Conceição pelas críticas e sugestões, assumindo a versão final como de minha exclusiva responsabilidade.
} 


\section{INTRODUÇÃO}

Deve-se fundamentalmente a Celso Furtado, em Formação Econômica do Brasil, a tese clássica de que o Brasil foi um dos primeiros países ocidentais a sair da crise iniciada em 1929, e que tal fato deveu-se à política intervencionista empreendida pelo governo para sustentar as exportações de café. Esta tese e seus desdobramentos já foram objeto de inúmeras discussões e polêmicas, envolvendo ardorosos defensores e contendores. Pretende-se aqui retomá-la para aprofundar a discussão em um ponto ainda não de todo solucionado pela literatura, muitas vezes até ignorado, mas de suma importância para a reconstituição da história econômica do período. Este diz respeito, mais precisamente, à intencionalidade e à consciência do governo quanto à consecução das expressivas taxas de crescimento verificadas na indústria de transformação a partir de 1933.

Para tanto, recorrer-se-á a contribuições do pensamento institucionalista para interpretar a política econômica do governo brasileiro na década de 1930 e, com isto, apontar alguns limites da tese amplamente difundida a partir de Celso Furtado. Talvez por restringir ou centrar sua análise nas políticas instrumentais - aqui definidas como fundamentalmente as políticas monetária, cambial e fiscal - as quais possuem uma lógica própria inerente a políticas de estabilização, Furtado acabou por entender o crescimento da indústria como conseqüência não intencional da política de valorização do café e de manutenção da renda nominal do setor, executada pelo governo seja pelo efeito negativo da crise nas finanças públicas e no balanço de pagamentos, seja pela importância econômica e política dos setores exportadores de café.

Entende-se que, se nem sempre estas políticas instrumentais são capazes de evidenciar intencionalidade, dificultando que de sua formulação ou execução se possam depreender claramente as intenções de seus formuladores, o mesmo não ocorre com instituições criadas, extintas ou alteradas. O exame destas pode mostrar-se valioso metodologicamente ao permitir, com maior facilidade e precisão, que sejam empiricamente reveladas intenções, planos e projetos, porquanto em geral resultam de atos deliberados, que precisam ser materialmente expressos não só "fisicamente" (caso de órgãos, institutos, ministérios, associações), como pela escrita (caso de leis, códigos e alguns símbolos) ou pela linguagem oral (caso de discursos e entrevistas, por exemplo).

Embora a influência das idéias institucionalistas na área de história econômica do Brasil só tenha começado a aparecer nos últimos anos, sendo ainda incipiente, sem dúvida nas últimas duas décadas houve um florescimento no meio acadêmico da escola institucionalista, em intensidade sem paralelo desde a inovadora contribuição de Veblen, que remonta ao final do século 19. Certamente ao longo do século 20 as idéias institucionalistas não foram esquecidas, haja vista nomes como Commons e Mitchell que, juntamente com Veblen, formam o tripé do "velho" institucionalismo norte-americano, crítico ao neoclassicismo, que também influenciou Galbraith e Myrdall, estes mais divulgadores das idéias institucionalistas que propriamente teóricos. 
A partir da década de 1960, essas idéias ganharam vigor seguindo duas vertentes. Uma, mais próxima ao neoclassicismo, a chamada Nova Economia Institucional, que aproxima o institucionalismo da microeconomia tradicional ao enfocar os custos de transação, a tecnologia e as formas institucionais de organização da firma, as falhas de mercado e os direitos de propriedade, embora crítica aos princípios de racionalidade substantiva e de maximização neoclássicas. Autores como Williamson e Douglass North são exemplos desta corrente cujo precursor seja possivelmente Coase (1993), em seu famoso artigo de 1937. A outra vertente, que se pode designar de neo-institucionalista ou institucionalista evolucionária, volta-se a resgatar a antiga tradição de Veblen, Commons e Mitchell, desde logo afastando-se das noções neoclássicas de equilíbrio e maximização e enfocando a importância do ambiente histórico e social na análise econômica, com ênfase na interdisciplinaridade.

Uma forma de apreender o debate dentro das várias vertentes do institucionalismo é através da sistematização do conceito de instituição subjacente a seus principais autores, como faz de Nelson (1995: p.80-82), já que por esta pode-se perceber mudanças de significados, ênfases e abrangências na utilização deste termo que variam de autor para autor. Assim, a antiga tradição entende por instituição algo semelhante a cultura, envolvendo crenças, valores, símbolos e padrões de comportamento; chama-se atenção para a complexidade envolvida nas instituições, com cunho fortemente sociológico, acentuando a importância da interdisciplinaridade. Já para um segundo grupo, que compreende a Nova Economia Institucional, instituição tem um sentido mais restrito, lembrando "regras do jogo", numa concepção mais próxima à teoria dos jogos. Mas há ainda uma terceira visão, a qual se assenta em uma definição de natureza mais histórica, associando instituição a estruturas, organizações ou conjunto de leis, abarcando, portanto, por exemplo, a moeda, o sistema jurídico, as corporações, o sistema financeiro e os organismos econômicos internacionais (para uma discussão mais aprofundada entre as várias correntes do institucionalismo, veja: Conceição (2000: cap.2).

Essas três definições, embora diferentes, não chegam a ser incompatíveis, no sentido que nada impede sua utilização conjunta em um estudo histórico, principalmente por enfatizarem aspectos relevantes que a amplitude e a riqueza que o termo instituição pode abarcar, ao associar-se à diversidade e à heterogeneidade de enfoques - nas palavras de Samuels, à sua fertilidade (Samuels, 1995, p.570). A terceira definição, entretanto, possui a vantagem de trazer consigo o caráter da historicidade, e por isso mais se coaduna ao objeto aqui abordado. Somam-se a esta as contribuições de Zysman (1994), para quem as instituições são fundamentais na reconstrução histórica porque moldam experiências nacionais e regionais concretas, possibilitando diferentes conformações históricas, necessariamente vinculando-as à forma de inserção no ambiente social e econômico. Assim, cada nação em seu curso histórico cria estruturas institucionais próprias para os diferentes mercados (de bens, de trabalho, de capital, de terra), e estas moldam tipos peculiares de comportamento empresarial e governamental.

Essa relação é de fundamental importância para a confirmação de nossa hipó- 
tese básica, segundo a qual a consciência do governo brasileiro na década de 1930, no que tange à opção industrializante, pode ser demonstrada pelas instituições criadas e alteradas no período. Para Zysman, os mercados estão enraizados (embedded) nas instituições políticas e sociais, são criações de governos e de políticos, "não podendo existir ou operar fora das regras e instituições, que estruturam compras, vendas e a própria organização da produção" (Conceição, 2000: p.65-66). Neste sentido, pode-se demonstrar que as instituições criadas e/ou modificadas na década de 1930 pelo governo brasileiro evidenciam sua opção industrializante, pois representam mecanismos, regras, arenas e espaços para, dentro do aparelho estatal e sob sua influência, reorientar a economia, definindo nova relação estado/empresariado/mercado/trabalhador.

\section{FURTADO E A INDUSTRIALIZAÇÃO COMO SUBPRODUTO DA DEFESA DO CAFÉ}

Já logo após sua primeira edição, em 1959, Formação Econômica do Brasil, de Celso Furtado, tornou-se marco nos estudos de história econômica. Justamente os capítulos 30 a 33, em que aborda a crise da economia cafeeira e o "deslocamento do centro dinâmico" - para usar sua expressão consagrada —, das atividades agro-exportadoras para o mercado interno, como resultado do impacto da crise internacional, constituem sua parte considerada mais criativa e que propiciou maior debate (Furtado, 1977: p.195). De certa forma, toda a obra foi escrita preparando o leitor para seu clímax, que ocorre nesses capítulos.

Como já se mencionou, a polêmica envolvendo a interpretação de Furtado sobre esse período assumiu vários contornos e propiciou inúmeros temas de pesquisa. Dentre os que ocuparam maior lugar na literatura, podem-se mencionar, dentre outros, o debate envolvendo a origem da indústria, se realmente o autor subestimara o crescimento industrial anterior a 1930 e se este resultara de "choques adversos" externos ou do próprio crescimento da economia exportadora; o fato de considerar como crescimento industrial o crescimento da produção, subestimando a expansão da capacidade produtiva; se o financiamento para garantir a política governamental anticíclica deveu-se fundamentalmente a crédito e a emissões, como acentua Furtado, ou a impostos, como afirmam alguns de seus críticos; e, finalmente, e sem a pretensão de esgotar os pontos polêmicos mais debatidos, se a política econômica governamental pode ser realmente entendida como keynesiana, mesmo que anterior à Teoria Geral de Keynes, ou se seguia ainda as regras da ortodoxia.

Não cabe aqui reconstituir esses debates, mas assinalar que a literatura pouco se debruçou na interpretação do significativo desempenho do setor industrial, que cresceu 11,2\% anuais entre 1933-39 (Villela e Suzigan, 1973: p.211-2), mais precisamente se este resultou de uma política governamental deliberada, se houve intencionalidade dos dirigentes em imprimir novos rumos à economia, ou se o "deslocamento do centro dinâmico" ocorreu sem uma intenção consciente por parte do governo. Esta questão faz sentido porque Furtado, a despeito de ressaltar os êxitos 
da política de manutenção de renda na superação da crise e de seu impacto positivo na indústria, interpretou-os como resultado de um salutar intervencionismo antiortodoxo, mas nunca defendeu a intencionalidade no que diz respeito ao crescimento industrial. Ao contrário, demonstra-se que Furtado entendeu o crescimento industrial da década de 1930 como fruto da política de defesa do café, que teria sido implementada pelo governo: (a) seja devido às exigências pragmáticas impostas pela crise, por sua repercussão no balanço de pagamentos e na arrecadação de impostos; (b) seja por razões de ordem política, frente à importância do setor cafeicultor e pela própria composição do governo, chamando atenção a seus compromissos conservadores, "oligárquicos" e "agraristas"; ou (c) seja, ainda, devido a um terceiro fator, assinalado em uma passagem, na qual se menciona não propriamente a política governamental, mas a decisão individual dos capitais privados, em busca de diversificação dos investimentos, já que nas atividades voltadas ao mercado interno havia maior perspectiva de lucro, frente à crise das atividades de exportação (Furtado, 1977, p.198).

Deve-se ressaltar que críticos de Furtado, como Peláez (1972, 1979), voltados a refutar a importância da política "keynesiana" de defesa do café para a indústria e em relativizar as transformações econômicas da década de 1930, pouco abordaram a questão da intencionalidade, até porque esta não era uma questão posta por suas abordagens. Explicando melhor: esta só faz sentido como tema de pesquisa ao admitir-se que efetivamente Furtado tenha acertado ao assinalar o "deslocamento do centro dinâmico" da economia em favor do mercado interno e da indústria, daí resultando a pergunta se o mesmo ocorreu ou não por uma ação deliberada do governo. Desta forma, a hipótese aqui levantada afirmando a consciência e a intencionalidade da política pró-indústria na década de 1930 no Brasil tem, como seu pressuposto, que efetivamente a tese de Furtado sobre o referido deslocamento esteja correta.

Mesmo que bastante conhecido, vale a pena reconstituir o pensamento de Furtado enfocando este aspecto, bem como citar passagens de sua obra, a fim de que não reste dúvida sobre a tese por ele defendida e algumas de suas implicações.

Sua argumentação, nos capítulos 30 a 33 de Formação Econômica do Brasil, parte da política cambial, com a desvalorização do mil-réis para enfrentar a crise do exportador e o estrangulamento externo, mas que, ao mesmo tempo, encarecia as importações - e, portanto, sem querer, ocasionara um efeito protecionista a favor da indústria nacional. Mas a crise diminuía também a arrecadação de impostos; o governo via-se forçado a partir para uma política monetária expansiva para contrabalançar a queda na receita tributária corrente, inclusive porque fora pelo crédito, viabilizado por emissão, que realizara os gastos públicos de sustentação de preço do café. Assim, as políticas monetárias e fiscais acabaram beneficiando o mercado interno não só por impedirem substancial queda na demanda agregada, como por baixarem taxas de juros: sem querer, acabavam favorecendo o setor industrial, embora seu objetivo se voltasse ao equilíbrio orçamentário e do balanço de pagamentos. Mesmo as tarifas protecionistas - embora menos enfatizadas por 
Furtado - , teriam sido adotadas devido o problema cambial e, portanto, também sem querer, acabaram tendo um efeito protetor à indústria.

Assim, em Formação Econômica do Brasil, afirma textualmente que se praticara "no Brasil, inconscientemente, uma política anticíclica de maior amplitude que a que se tenha sequer preconizado em qualquer dos países industrializados" (1977:

p.192, grifos meus, assim como os a seguir). Em uma única passagem transparece a dúvida sobre a consciência da política econômica, mas com respeito à economia do café, e não com relação ao setor industrial: "Esses resultados, de grande significação para o futuro imediato da economia brasileira, são um reflexo imediato das dimensões catastróficas da crise do café e da amplitude com que foram defendidos, conscientemente ou não, os interesses da economia cafeeira (p.201). A tese da não consciência ou da não intencionalidade do governo com relação ao desenvolvimento da indústria é clara; em outros momentos, abandona esta dúvida para defender explicitamente que "a recuperação da economia brasileira, que se manifesta a partir de 1933, não se deve a nenhum fator externo e sim à política de fomento seguida inconscientemente no país e que era subproduto da defesa dos interesses cafeeiros" (p.193, grifos meus).

A política econômica, por conseguinte, em seu entender, não só se voltara à sustentação dos preços do café por uma questão de finanças públicas, mas para explicitamente defender os interesses da economia cafeeira. Assim, tanto a recuperação econômica como o mudança do eixo principal da economia brasileira para a indústria e para o mercado interno não decorreram de intenção ou consciência governamental neste sentido; são antes, em suas palavras, "reflexo imediato" da crise do café e "subproduto" dos interesses deste setor.

É importante também demonstrar que esta tese está presente não só em Formação Econômica do Brasil, mas é recorrente no pensamento de Furtado, encontrada em outras obras suas ao abordar o mesmo tema. Em Desenvolvimento e Subdesenvolvimento, de 1961, voltou a afirmar que, diante da magnitude da crise dos anos trinta, o "poder Público decidiu, então, ir mais longe e garantir mercado aos produtores de café" e que "essa medida tomada para proteger o setor exportador resultou ser de extraordinário alcance como defesa do nível interno de emprego" (Furtado, 1961, p.237). A industrialização como subproduto desta política é retomada ao afirmar: "Visando a defender o setor externo - preocupação constante da classe dirigente - o Poder Público criou condições para uma rápida ampliação do setor industrial ligado ao mercado interno" (p.238). A tese da não percepção da envergadura e das conseqüências da política implementada reforça-se ao frisar que "a marcha para a industrialização cumprida nos últimos decênios foi realizada sem que existisse no país uma clara compreensão das modificações que se estavam operando na estrutura econômica". Só a partir da guerra, na década de 1940 , que se começaria a tomar "consciência do caminho percorrido pela industrialização" (p.244).

Já em Dialética do Desenvolvimento, cuja primeira edição apareceu em junho de 1964, Furtado argumenta que o movimento político de 1930 permitiu "renovar as cúpulas dirigentes, afastando os grupos mais diretamente ligados à economia de 
exportação" (Furtado, 1964: p.111-13, de onde foram extraídas esta e as demais citações a seguir). O fato de os novos dirigentes provirem "de áreas menos ligadas aos mercados externos, como era o Rio Grande do Sul" teria contribuído para "uma percepção mais direta da realidade", com a ressalva de que a política imprimida "não obedecesse a qualquer diretriz conscientemente estabelecida". Seguiu-se, então, uma fase que denominou de "realismo político", na qual "se tentou enfrentar grandes males com grandes remédios, sem maiores preocupações de coerência e sem muita consciência do que dai decorreria". Mas, logo a seguir, retoma sua tradicional tese segundo a qual o objetivo desta política "era aliviar a cafeicultura, transferindo para o conjunto da população os prejuízos que de outra forma se concentrariam nesse setor". Com ela, entretanto, "o país entra numa fase de modificações estruturais irreversíveis, cujo alcance somente mais tarde seria percebido". A industrialização é novamente entendida como "decorrência da crise", ou seja, "subproduto do realismo na defesa dos interesses cafeicultores".

Finalmente, em Formação Econômica da América Latina, de 1969, mais uma vez frisou que a partir da crise de 1929 a "industrialização seria principalmente induzida pelas tensões estruturais provocadas pelo declínio, ou crescimento insuficiente, do setor exportador" (Furtado, 1970: p.131). Embora nesta obra reconheça certas ações e instituições criadas pelo governo como importantes, como a eliminação das barreiras entre estados, visando unificar o mercado nacional, a criação da Companhia Siderúrgica Nacional e o treinamento de mão-de-obra voltada ao setor industrial, Furtado reafirmou que os vínculos maiores da política do governo varguista - ao qual denominou autoritarismo esclarecido - eram com os interesses exportadores, mesmo que esta interpretação lhe causasse certo embaraço para explicar a revolta paulista de 1932, que chegara à radicalização de um movimento armado: "O governo Vargas, não obstante a contra-revolução inspirada pelos grupos tradicionalistas em 1932, levou adiante uma política de compromisso com os grupos cafeicultores, cuja produção foi adquirida mesmo que em grande parte tivesse de ser destruída” (p.143).

Se há notável coerência por parte de Furtado ao defender o mesmo ponto de vista em diferentes obras no que tange às razões da política econômica implementada na década de 1930 e de suas conseqüências não intencionais sobre o setor industrial, ocasionadas sem que houvesse uma ação estatal consciente neste sentido, o mesmo não ocorre ao tentar explicitar a que segmentos sociais o governo mais se aproximava ou nele se faziam representar. Em uma mesma obra, algumas vezes, defende pontos de vista conflitantes, ou pelo menos de difícil compatibilização sem uma série de qualificações e mediações. Este fato, entretanto, não deve ser mencionado como mera curiosidade ou para apenas chamar atenção para uma eventual incoerência que se esgota em si mesma. Tudo sugere, ao contrário, que o mesmo decorre da deficiência da própria explicação de Furtado de ver a industrialização como "subproduto" da política de defesa dos interesses do café e de ter ocorrido sem qualquer consciência e intenção. Esta se choca frontalmente com a própria relevância que pretende ressaltar no deslocamento do "centro dinâmico da economia", contrariando sua própria percepção quanto ao vulto e a profundidade das transformações. 
Em Formação Econômica do Brasil, embora repita várias vezes, como se mostrou, que a política econômica voltava-se à estrita defesa dos interesses do café, em uma nota de rodapé ensaia uma explicação para o movimento revolucionário de 1930, associando-o aos militares, às populações urbanas, à burocracia civil e aos grupos industriais — ou seja, aos segmentos "modernos" da sociedade (1977: p.201). Já em Desenvolvimento e Subdesenvolvimento predomina o tom crítico ao governo, chegando a afirmar que a política de retenção de estoques de café visava apenas dar uma aparência de normalidade: "Predominava no país um conservadorismo voltado para a restauração de um passado glorioso" (1961: p.235). E a seguir: "As classes dirigentes, afeitas a raciocinar em termos de economia de exportação de produtos primários, careciam de objetividade para diagnosticar os problemas decorrentes das transformações em curso" (p.244).

Em Dialética do Desenvolvimento, como foi antes mencionado, afirma que o movimento político de 1930 renovara as cúpulas dirigentes, "afastando os grupos mais diretamente ligados à economia de exportação" (p.111). Mas, logo adiante, surpreendentemente assevera que a partir de 1930 "as classes que dirigem o país são, no essencial, as mesmas do período anterior” (p.113). As mesmas classes, mas com ideologia diferente; recorre-se, então, ao "oportunismo", para explicar os novos rumos impressos à economia: "Contudo, o oportunismo político dos novos dirigentes, muitos menos rígidos em seus esquemas ideológicos que os homens de Minas de São Paulo que antes haviam governado a República, abrira indiretamente a porta à industrialização" (p.113).

Já em Formação Econômica da América Latina, afirma, num extremo oposto, ao comparar as revoltas de 1930 do Brasil com o movimento político similar ocorrido na Argentina, que a "Revolução de 1930" no Brasil fora mais uma "sublevação popular (sic) que um levante militar", permitindo que "se deslocasse do Poder a oligarquia cafeeira, sob pressão de grupos periféricos do Nordeste e do extremo sul”. Daí o autoritarismo esclarecido de Vargas, em contraste com a democracia apenas formal da União Cívica Radical (1970: p.143).

Assim, não resta dúvida de que, para Furtado, o crescimento industrial brasileiro na década de 1930 foi subproduto (para usar uma expressão sua) da defesa do setor cafeicultor e, tudo sugere, perseguindo o objetivo maior de evitar o aprofundamento da crise nas finanças governamentais. A tese da não intencionalidade é recorrente em sua obra e, mesmo sem ter uma definição clara e única sobre as relações entre o grupo dirigente e o setor agroexportador, ressaltou mais este vínculo do que com os interesses industriais. Na verdade, quanto a este último não há nenhuma referência direta nos trabalhos analisados.

\section{EVIDÊNCIAS DA CONSCIÊNCIA INDUSTRIALIZANTE}

Em contraste com a posição de Furtado, podem-se encontrar vários indícios e fatos que ajudam a evidenciar que o governo brasileiro, na década de 1930, conscientemente buscava a industrialização e a considerava uma alternativa a ser cons- 
truída para a economia brasileira. Isto não significa dizer que esta consciência já estivesse plenamente configurada logo após a "Revolução de 30". Evidentemente ela não nasceu acabada, mas foi se fortalecendo ao longo da década; surpreende, entretanto, que já nos primeiros anos, em seu início, encontrem-se evidências neste sentido. Chama-se atenção, neste aspecto, para as instituições criadas e alteradas na década de 1930 pelo governo, em atitudes que de forma alguma podem ser entendidas como decorrência linear da política de valorização do café, ou cuja implementação tenha se verificado sem intenção deliberada de defender e promover o crescimento industrial. Da mesma forma, esta intencionalidade não deve ser entendida como uma política implementada "pelo alto" por um Estado clarividente e acima de tudo e de todos. Ao se chamar a atenção para a consciência da política governamental em defesa da indústria, não se pode negligenciar que a mesma contou para sua consecução e fortalecimento com o trabalho dos próprios industriais da época, com relativa organização em órgãos associativos, capazes de fazer o governo adotar medidas e, inclusive, voltar atrás em decisões já tomadas. Neste aspecto, o trabalho de Leopoldi (2000) é fundamental ao trazer à tona as associações empresariais e sua importância para os rumos da economia e da política, muitas vezes subestimadas em prol de análises que se centram no grupo dirigente e nas ações estatais sem dar a necessária ênfase às relações entre estes e o empresariado, tendo por corolário a passividade deste frente políticas governamentais pró-ativas..

Podem-se mencionar inicialmente leis voltadas aos interesses industriais, como o Decreto n ${ }^{\circ} 19.739$, de 7 de março de 1931, que proibia a importação de máquinas e equipamentos para certos segmentos da indústria. Embora se possa argumentar que os efeitos para o setor industrial poderiam, à primeira vista, ser negativos, devese lembrar mais uma vez que este não era o entendimento à época, pois a decisão decorria de pressão dos próprios líderes empresariais, para quem a crise de superprodução seria mais grave caso novas unidades fabris fossem instaladas (Observador econômico e financeiro, 1937: p.91). E a medida, como se sabe, não atrapalhou o desempenho da indústria, haja vista as taxas expressivas de crescimento verificadas a partir de 1933 e a prorrogação da vigência do decreto, atendendo reivindicação empresarial, até março de 1937.

A importação de bens de capital para o setor industrial contaria com apoio governamental, com a assinatura, em 1935, de tratado de comércio com os Estados Unidos. Este concedeu vantagens a alguns produtos de exportação brasileiros (café, borracha, cacau) em troca de redução de $20 \%$ a $60 \%$ na importação de certos artigos norte-americanos, como máquinas, equipamentos, aparelhos e aços. Conquanto alguns líderes empresariais à época tenham-se mostrado críticos ao tratado, pois este também permitia a importação de certos bens de consumo, sua assinatura não deixa de demonstrar a intenção governamental de romper com o antigo papel de importador destes bens, ao incluir com ênfase - e esta era a novidade, em termos históricos -, os bens de capital e intermediários necessários à indústria. É razoável supor que na crise os industriais já estabelecidos, neste caso, mantinhamse na posição de preferir incentivos governamentais à utilização da capacidade 
existente a ver novas instalações serem introduzidas, com equipamentos importados. Já o comportamento do governo mostra seu interesse em modificar a pauta de importações, aprofundando o crescimento industrial e em coerência com o modelo substitutivo, ou seja, mudando-a qualitativamente através da perda da posição relativa dos bens de consumo frente à elevação dos bens de capital, intermediários e insumos industriais.

Pode-se lembrar, em adição, a política protecionista adotada com a reforma tributária de 1934. Embora não haja consenso na literatura sobre sua intencionalidade, temos de convir que a proteção decorrente de tarifas difere da resultante de desvalorização cambial, pois esta última pode - e geralmente é - adotada com vistas a fins que não a proteção ao setor industrial, ao contrário de políticas tarifárias, em que esta possibilidade existe, embora também possam ser adotadas para atender a fins diversos, inclusive buscar o equilíbrio do balanço de pagamentos.

No caso da reforma tributária de 1934, a despeito de controvérsias, há o fato inconteste que a mesma atendeu a pressão de industriais da época, como Roberto Simonsen e Euvaldo Lodi, e resultou em um aumento da tarifa específica agregada em torno de 15\% (Abreu: p.86). Como houve em 1935 uma desvalorização do milréis que, ao elevar o preço dos importados, acabou reduzindo o peso da tarifa, podese subestimar sua importância, mostrando que a política cambial foi quem, na prática, representou maior proteção para a indústria doméstica. Entretanto, mesmo que isto seja verdadeiro como resultado, não pode apagar a intencionalidade da reforma tributária - adotada antes da desvalorização cambial, portanto quando a indústria não fora ainda beneficiada com a mudança no câmbio. Neste aspecto, cabe lembrar que o governo adotou justamente a política defendida pelos industriais. Se, para o analista atual, pode parecer insignificante, certamente não o era para líderes empresariais devotados à causa da indústria, como Euvaldo Lodi, que em carta ao ministro da Fazenda afirmou que o novo código tarifário "deixara a melhor impressão nos meios industrias" (Leopoldi, 2000: p.116).

Quanto à política creditícia voltada diretamente à indústria, mais que o crescimento real do volume de crédito na década de 1930 deve ser salientada a criação da Carteira de Crédito Agrícola e Industrial do Banco do Brasil em 1937. Esta marca a institucionalização de um órgão voltado especificamente à concessão de crédito para criação de novas indústrias e expansão das já existentes, concedendo empréstimos em prazos até dez anos. Não se trata ainda de um banco de desenvolvimento, que Hirschman considera, junto com a criação de empresas estatais, como instrumento de ação direta necessário para caracterizar uma política deliberada de desenvolvimento (Apud Suzigan, 2000: p. 41). Entretanto, não deixa de ser um embrião de uma nova relação entre o Estado e o empresariado industrial, já que institucionaliza o crédito em uma carteira específica, teoricamente seletiva por critérios burocráticos, diferente da forma mais personalizada e pontual com que se concedia crédito até então, principalmente para investimento (já que para capital de giro era usual, mesmo em bancos privados).

A intencionalidade destas ações fica mais evidente quando a elas se associa o próprio discurso governamental. Já em 1931, Vargas afirmava a necessidade de 
protecionismo deliberadamente para proteger a indústria nascente: "O protecionismo industrial das matérias-primas do país é fator decisivo, sem dúvida, ao nosso progresso econômico. É justo, por isso, que se estimule, mediante política tarifária, conduzida sem excessos. As tabelas das alfândegas devem refletir estes critérios" (Vargas, 1938, v. 1, p. 163). Nesta época associava-se a indústria ao progresso econômico. Em meados da década, este será substituído por desenvolvimento econômico, como no discurso pronunciado a 7 de setembro de 1936: "Atingimos elevado estágio de desenvolvimento cultural, institucional e econômico. (...) Já não somos um país exclusivamente agrário, jungido à luta pelos mercados consumidores de matérias-primas e esmagado pelo peso das aquisições de produtos industriais" (Vargas, 1938: v. 4, p. 182).

Desenvolvimento, então, paulatinamente transformara-se em sinônimo de industrialização. Passava a ser, por excelência, a condição necessária para o país se desenvolver, ou seja, melhorar seus indicadores econômicos e sociais; precisava-se romper com o passado agrário, do marasmo rural e das oligarquias retrógradas. $\mathrm{O}$ desenvolvimentismo, assim, foi-se formando e se consolidando como ideologia, ao nortear e justificar o reordenamento de leis e práticas de política econômica, bem como mudanças e criação de instituições. Foram se formando novas crenças, valores, símbolos e padrões de comportamento - ou seja, o amplo significado abarcado pela palavra instituição e que enfatiza sua importância e complexidade, que de forma alguma pode ser reduzido apenas a órgãos, mas abarca todo um conjunto de regras, normas, comportamentos e símbolos.

Em outro pronunciamento, ao final do mesmo ano de 1936, registra-se a explicitação da tese de que o desenvolvimento era a tarefa principal do poder público, que possuía etapas a serem vencidas e que este novo relacionamento entre Estado e iniciativa privada não ocorreria em prejuízo desta última, "antes, amparando-a e favorecendo o surto de novas culturas e indústrias" (Vargas, 1938: v. 4, p. 209). Tratava-se, portanto, de uma nova era a ser construída; o Estado Novo, em seu próprio nome, encarregava-se de expressá-la simbolicamente. Todas essas passagens não deixam dúvida sobre a consciência da substituição de importações e de sua importância para o país. Como entender como "subproduto" da política de valorização do café políticas tão claramente implementadas e defendidas explicitamente como voltadas a impulsionar o setor industrial?

A consciência industrializante manifestava-se, à época, também na preocupação com as riquezas do subsolo; a possibilidade de nova guerra, por sua vez, aproximava o exército da defesa da industrialização (fabricação de armas e projéteis, a qual exigia produção de ferro e aço) e da nacionalização das riquezas minerais. Tratase, neste caso, de regulamentar algo caro à Nova Economia Institucional: o direito de propriedade. Novas instituições - leis, códigos, órgãos, escolas, laboratórios, institutos - faziam-se necessárias, inclusive para estabelecer os limites da propriedade privada frente à estatal, e da propriedade de estrangeiros com relação a proprietários nacionais. Mas já em 1933, portanto ainda no início da década, previase a criação, junto ao Ministério da Agricultura, do Instituto de Tecnologia, que se vincularia à Diretoria Geral de Pesquisas Científicas. Previa-se, ainda, a 
criação de duas diretorias, das Minas e das Águas, e três centros de pesquisa vinculados à extração mineral: Instituto Geológico e Mineralógico, Laboratório Central de Indústria Mineral e Escola Nacional de Química. O Código de Minas e o Código de Águas, ambos bastante centrados na regulamentação do direito de propriedade, datam de 1934.

Essas ações culminaram com a intervenção direta do governo na produção industrial, com a criação da Companhia Siderúrgica Nacional, com a Usina de Volta Redonda, e com a Companhia Vale do Rio Doce, no início da década de 1940. Mas já na década de 1930 Vargas afirmava: "Nenhum outro dos problemas que dizem respeito ao desenvolvimento econômico do país sobreleva em importância ao da exploração das nossas jazidas minerais”. Para tanto, seria insuficiente a pequena siderurgia, normalmente incapaz de atender a futura demanda a resultar do crescimento industrial acelerado (Vargas, 1938, v. 1, p. 100). Por isso, defendia-se explicitamente a criação da siderurgia em "grande escala". Em 1934, ao discursar para um grupo de militares, Vargas anunciou a iniciativa do governo federal de criar fábrica de projéteis de artilharia, de materiais contra gases e de viaturas em Curitiba; que decretara a criação de fábricas de espoletas e estojos de artilharia e de canos e sabres; que ampliara a fábrica de cartuchos de infantaria e o Arsenal de Guerra do Rio Grande do Sul; e, finalmente, que enviara técnicos à Europa a fim de "estudarem os aperfeiçoamentos necessários à nossa indústria militar nascente" (Vargas, 1938, v. 3, p. 164).

Desde o início da década de 1930 o governo implementou política de criar órgãos estatais voltados a setores específicos da economia. Dentre as instituições criadas, podem-se citar como as que dizem respeito mais diretamente à indústria: o Ministério do Trabalho, Indústria e Comércio, em 1930; o Departamento Nacional do Trabalho e o Instituto do Açúcar e do Álcool, em 1933; o Conselho Federal do Comércio Exterior, o Plano Geral de Viação Nacional e a Comissão de Similares, em 1934; e o Conselho Técnico de Economia e Finanças, em 1937.

A partir do Estado Novo, e devido o contexto de guerra, esta política de criação de órgãos, conselhos e institutos intensificou-se. Datam de 1938 o Conselho Nacional do Petróleo, o Departamento Administrativo do Serviço Público (DASP), o Instituto Nacional do Mate e o Instituto Brasileiro de Geografia e Estatística IBGE); de 1939, o Plano de Obras Públicas e Aparelhamento de Defesa e o Conselho de Águas e Energia; de 1940, a Comissão de Defesa Nacional, o Instituto Nacional do Sal, a Fábrica Nacional de Motores e a Comissão Executiva do Plano Siderúrgico Nacional; de 1941, além da Companhia Siderúrgica Nacional, o Instituto Nacional do Pinho, a Comissão de Combustíveis e Lubrificantes e o Conselho Nacional de ferrovias; de 1942, o Serviço Nacional de Aprendizagem Industrial (SENAI), o Banco de Crédito da Borracha e a Comissão do Vale do Rio Doce; de 1943, a Consolidação das Leis do Trabalho (CLT), a Companhia Nacional de Álcalis, a Comissão de Financiamento da Produção, a Coordenação de Mobilização Econômica, Fundação Brasil Central, Siderúrgica Social da Indústria (SESI) e Plano Nacional de Obras e Equipamentos; de 1944, o Conselho Nacional de Política Industrial e Comercial, o Serviço Nacional do Trigo, o Instituto Nacional do Pinho 
e a Comissão de Planejamento Econômico; e, finalmente, de 1945 a Superintendência da Moeda do Crédito, que iria voltar-se a regular uma das mais importantes instituições: a moeda e a política monetária.

Nota-se que a maior parte destes órgãos, como sugere o próprio nome dos mesmos, diz respeito direta ou indiretamente à indústria, a contar que os voltados à agricultura também vinculam-se à agroindústria, e que esta, ao abarcar o que à época chamava-se "indústria natural", perfazia mais de $80 \%$ do valor agregado pela indústria de transformação. Por outro lado, instituições não propriamente voltadas à defesa de interesses corporativos da indústria, como o Conselho Federal de Comércio Exterior, legalmente arrolavam-se entre suas atribuições debater e sugerir medidas com relação às importações, incluindo o protecionismo. Além disso, cabia-lhe propor "soluções técnicas" para problemas vinculados à promoção da indústria nacional, bem como a criação de departamentos e institutos relacionados com produtos minerais e agrícolas. Assinala, com isso, a diferença fundamental entre o impacto e o significado da criação de órgãos estatais e da legislação corporativista da década de 1930 sobre os trabalhadores e sobre o empresariado. Enquanto sobre os primeiros representou fundamentalmente um atrelamento ao Estado, que passou a controlar a organização sindical, estabelecendo as bases para o populismo das décadas de 1940 e 1950, para os empresários mais que atrelamento ou submissão significou uma aproximação às esferas estatais decisórias, a abertura de canais diretos entre a burocracia e os dirigentes das federações e confederações patronais. No Estado Novo, quando as instituições liberais de representação foram suprimidas e as casas legislativas fechadas, estes órgãos criados dentro do Poder Executivo transformaram-se em arenas decisórias e de canalização das demandas, firmando um tipo de aliança entre o grupo dirigente e o empresariado (Fonseca, 1989: p. 205, 297).

Ressalta-se, sem dúvida, a grande complexificação do aparelho estatal, centralizando a arrecadação, derrubando barreiras interestaduais e criando instituições econômicas com âmbito de atuação em escala nacional, com o intuito de integrar o mercado e centralizar decisões. A criação do Departamento Administrativo do Serviço Público - DASP, em 1938, bem como de seus órgãos homônimos nos estados, os "daspinhos", vieram no sentido de tentar organizar uma burocracia estatal mais assentada em critérios de mérito e competência, sob a égide da ideologia estado-novista de substituir a política pela administração. Como frisa Sônia Draibe (1985: p. 83-4), nesses aparelhos estatais começaram a se gestar políticas nacionais. A análise desta autora, embora sem qualquer pretensão de questionar a tese consagrada por Furtado e sem abordar explicitamente a consciência e a intencionalidade da industrialização, é possivelmente a que dá mais elementos para sua defesa ao enfatizar as mudanças no aparelho do estado ou, como prefere, em sua "ossatura material", mostrando como esta centralização administrativa associou-se ao desenvolvimento industrial.

Cabe mencionar, finalmente, a política do governo com relação aos trabalhadores, essencial para detectar-se a existência de um projeto industrializante. $O$ fato de a indústria não poder ser considerada mero "subproduto" da defesa dos inte- 
resses do café pode em boa parte ser evidenciado pela forma com que o governo passou a envolver-se nas políticas relativas ao trabalho, considerando como questão de estado sua regulamentação, reconhecendo os conflitos como "de classe", criando instituições para mediá-los, bem como para educar e preparar mão de obra para as atividades produtivas, não só rurais como urbanas - o comércio e a indústria.

$\mathrm{Na}$ área de educação, destaca-se a reforma educacional de Francisco Campos, iniciada já em 1931. Esta visava abandonar o ensino exclusivamente considerado teórico e preparador de elites, os "bacharéis", ainda no essencial o mesmo que havia sido introduzido no país pelos jesuítas, centrado nas disciplinas ditas "humanísticas": latim, retórica, francês, filosofia, história, geografia e literatura. Ao lado deste, deverse-iam criar cursos técnicos e profissionalizantes, centrados em áreas voltadas diretamente à produção como engenharia, agronomia e contabilidade. Tanto Vargas como Francisco Campos afirmam com todas as letras que a criação de riqueza depende da produtividade, e que esta se vincula à qualificação e às condições físicas dos trabalhadores; estes são vistos como "capital humano aplicável ao aproveitamento integral das nossas condições excepcionais de riqueza" (Vargas, 1938, v. 3: p. 246).

Considerar o trabalhador capital humano certamente está longe do imaginário das elites agrárias. Não é por acaso que a legislação trabalhista restringe-se ao setor urbano da economia, excluindo os trabalhadores rurais. Além de mostrar os compromissos entre os setores agrários e o governo, esta exclusão ajuda a revelar seu caráter nitidamente urbano, principalmente industrial, no sentido que é uma questão posta pelo aparecimento e crescimento da economia urbano-industrial e tem sua razão de ser vinculada à perspectiva de seu desenvolvimento. Conquanto excluído da legislação trabalhista, o campo aparece no discurso ao se apregoar a necessidade de aumentar sua produtividade, principalmente quando se defende a criação de uma "Universidade do Trabalho", de onde deveria sair "no futuro, a legião dos nossos operários, dos nossos agricultores, dos nossos criadores, em suma, a legião dos obreiros dos campos e das fábricas” (Vargas, 1938: v. 2, p. 118-9). Mais uma vez a criação e as modificações nas estruturas institucionais auxiliam decisivamente para revelar a intencionalidade e a consciência dos dirigentes, principalmente quando associadas à análise do discurso, o que nem sempre ocorre com o acompanhamento das políticas monetária, cambial e fiscal.

É na área do trabalho que ocorrem mudanças institucionais mais significativas, e estas evidenciam claramente seus vínculos com um projeto de industrialização, um rompimento com a visão de mundo agrarista até então dominante, fazendo emergir novas crenças, valores, símbolos e padrões de comportamento. Menos de um mês após a posse de Vargas, em 26 de novembro de 1930, foi criado o Ministério do Trabalho, Indústria e Comércio, simbolicamente denominado por Vargas de "ministério da revolução" (Vargas, 1938: v. 3, p. 24).

É verdade que antes de 1930 já havia leis sociais, mas geralmente específicas a determinadas categorias. A partir de então, as leis passaram a ser universalizadas, sua implementação e fiscalização realizadas por órgãos estatais, como as Juntas de Con- 
ciliação e Julgamento, encarregadas de resolver dissídios, criadas em 1932, ano também em que surge a carteira do trabalho, maior símbolo do emprego formal e documento obrigatório para reivindicar direitos trabalhistas. Evidentemente que esta legislação, fortemente inspirada na Carta del Lavoro italiana, insere-se perfeitamente no contexto internacional da época, marcado pela descrença nas instituições liberais e pelos regimes totalitários, mas é adaptada à realidade brasileira, ou seja, às suas instituições, como evidencia o caso da exclusão dos trabalhadores rurais.

A legislação trabalhista da década de 1930, mais que trazer "benefícios" aos trabalhadores, voltou-se à regulamentação do mercado de trabalho e à organização burocrática da estrutura sindical. A criação das instituições e o controle estatal precederam as leis voltadas a assegurar direitos sociais, como salário mínimo, $13^{\circ}$ salário, férias e previdência. Esta institucionalização dos conflitos e das arenas em que os mesmos deveriam expressar-se é por demais definidora e reveladora das intenções governamentais. Tratava-se, neste aspecto, de regular e regulamentar o mercado de trabalho e as novas relações de propriedade, temas caros às contribuições teóricas institucionalistas.

Pode-se indagar até que ponto o governo tinha consciência da profundidade destas mudanças, mas dificilmente pode-se entendê-las como ato fortuito, fruto do acaso, desvinculado dos novos rumos impressos à economia. Até porque Vargas em várias ocasiões recorreu a argumentos históricos para justificar a nova legislação trabalhista, como em discurso proferido na comemoração do primeiro ano de sua posse, em outubro de 1931. Nesta ocasião, com rara clarividência expôs que o fim da escravidão não trouxera de imediato novas leis para substituir as antigas; a República Velha omitira-se quanto à regulamentação do trabalho assalariado, de maneira que era preciso organizá-lo "em bases racionais", com novas leis, novas instituições, novos costumes e novos hábitos (Vargas, 1938: v. 1, p. 53 e seguintes; v. 3, p. 15 e seguintes). O alcance e o significado de discursos como estes não podem ser ignorados ao se abordar a consciência e a intencionalidade das mudanças pelos personagens da história e, somados a seus atos, são capazes de revelar suas intenções.

\section{CONCLUSÃO}

Pode-se concluir que, ao contrário do que argumentou Celso Furtado na Formação Econômica do Brasil e em outras obras, a industrialização brasileira na década de 1930 não pode ser reduzida a mero subproduto da defesa dos interesses cafeeiros, ou da política de valorização do café. Ao centrar-se nas políticas econômicas instrumentais - monetária, cambial e fiscal —, Furtado não explorou a ação estatal em um sentido mais amplo, englobando a criação e /ou alteração de leis, códigos, órgãos, ministérios, regulamentação de relações de propriedade, enfim, toda uma rede que pressupõe regras, normas e comportamentos que passaram a caracterizar toda uma época, enfim, instituições que revelam a consciência e a intencionalidade do governo de direcionar a economia para o mercado interno, sob a liderança do setor industrial. 
Através de uma metodologia em que estas variáveis institucionais são incorporadas, em associação à análise do discurso oficial, pode-se detectar evidências empíricas suficientes para se considerar a hipótese da consciência e da intencionalidade muito mais aceitável para interpretar as ações e atitudes do governo brasileiro naquela década.

\section{REFERÊNCIAS BIBLIOGRÁFICAS}

ABREU, Marcelo de Paiva (1989) A Ordem do Progresso: Cem Anos de Política Econômica Republicana, 1889-1989. Rio de Janeiro: Campus.

COASE, Ronald H. (1993) “Nobel Lecture: The Institutional Structure of Production”. In: WILLIAMSON, Oliver \& WINTER, Sidney G. The Nature of the Firm: Origins, Evolution, and Development. New York/Oxford: Oxford University Press.

CONCEIÇÃO, Octavio Augusto Camargo (2000) “Instituições, Crescimento e Mudança na Ótica Institucionalista”. Porto Alegre (Tese de doutorado, CPG Economia/UFRGS).

DRAIBE, Sônia (1985) Rumos e Metamorfoses: Um Estudo sobre a Constituição do Estado e as Alternativas da Industrialização no Brasil, 1930-1960. Rio de Janeiro: Paz e Terra.

FONSECA, Pedro Cezar Dutra (1969) Vargas: O Capitalismo em Construção. São Paulo: Brasiliense.

FURTADO, Celso (1977) Formação Econômica do Brasil. 15.ed. São Paulo: Nacional.

(1961) Desenvolvimento e Subdesenvolvimento. [s.1], [s.ed.].

(1964) Dialética do Desenvolvimento. Rio de Janeiro: Fundo de Cultura.

(1970) Formação Econômica da América Latina. 2 ed. Rio de Janeiro: Lia.

LEOPOLDI, Maria Antonieta P. (2000) Politica e Interesses na Industrialização Brasileira; As Associações Industriais, a Política Econômica e o Estado. São Paulo: Paz e Terra.

MONASTÉRIO, Leonardo Monteiro (1995) “A Economia Institucional-Evolucionária de Thorstein Veblen”. Porto Alegre (Porto Alegre, Dissertação de Mestrado).

NELSON, Richard R. (1995) "Recent Evolutionary Theorizing About Economic Change”. Journal of Economic Literature (33): 48-90, mar.

OBSERVADOR econômico e financeiro (1937).

PELÁEZ, Carlos Manuel (1972) História da Industrialização Brasileira. Rio de Janeiro: APEC. (1979) História Econômica do Brasil. São Paulo: Atlas.

SAMUELS, Warren J. (1995) “The Present State of Institutional Economics". Cambridge Journal of Economics. v. 19: 569-590.

SUZIGAN, Wilson (2000) Indústria Brasileira: Origem e Desenvolvimento. São Paulo: Brasiliense, 2000. VARGAS, Getúlio. A Nova Política do Brasil. Rio de Janeiro: José Olympio, 1938-1947. 11 $\mathrm{v}$.

VILLELA, Annibal e SUZIGAN, Wilson (1973) Política do Governo e Crescimento da Economia Brasileira. Rio de Janeiro: IPEA/INPES, 1973.

ZYSMAN, John (1994) “How Institutions Create Historically Rooted Trajectories of Growth". Industrial and Corporate Change. v.3 (1): 243-283. 